\title{
ИДЕНТИФИКАЦИЯ ОТХОДОВ БУРЕНИЯ И ИХ ИСПОЛЬЗОВАНИЕ
}

\author{
Третьяк Александр Александрович1, \\ 13050465@mail.ru
}

\author{
Яценко Елена Альфредовна 1 , \\ tksiww@yandex.ru
Онофриенко Сергей Александрович 1 , 13050465@mail.ru

\author{
Карельская Екатерина Витальевна' ${ }^{1}$ \\ karelskaya_1992@mail.ru \\ 1 Южно-Российский государственный политехнический университет (НПИ) им. М.И. Платова, \\ Россия, г. Новочеркасск, ул. Просвещения, 132.
}

\begin{abstract}
Актуальность исследования обусловлена необходимостью решать экологические вопросы, возникающие при сооружении нефртяных и газовых скважин. Процесс идентисрикации отходов, образующихся при строительстве скважин, и использование их для нужд народного хозяйства являются актуальными задачами в настоящее время. Вопросы рециклинга бурового раствора включают в себя: разделение раствора на обезвоженную твердую фразу (буровой шлам) и дисперсную среду (буровой раствор); изготовление из бурового шлама различных видов сырья: повторное использование бурового раствора. С целью интенсификации процесса отделения бурового шлама от раствора предлагается использовать омагничивание. Предложена принципиальная схема очистки бурового раствора с использованием блока омагничивания. Установлено, что омагничивание бурового раствора способствует ускорению выпадения шлама из раствора. Предложена технология получения пропанта из бурового шлама с использованием попутного газа для обжига и мобильного комплекса, работающего непосредственно в полевых условиях, на месторождениях. В статье приведена принципиальная схема мобильной установки для переработки бурового шлама. Пропант, приготовленный из бурового шлама, предлагается использовать для гидроразрыва пласта на месторождениях, расположенных в этом районе. Предлагаемые разработки по рециклингу бурового раствора позволят тешить проблему обращения с отходами непосредственно на участках буровых работ, что даст значительный экономический эфрфект для буровых компаний.

Цель: оценить вопросы рециклинга бурового раствора; решить вопросы по ускоренному отделению шлама от бурового раствора за счет использования магнитного поля; разработать мобильную установку для переработки бурового шлама с использованием для обжига пропанта попутного газа; на разработанную технологию получения пропанта из отходов бурения подать заявку на изобретение и получить патент.

объекты: шлам, получаемый при сооружении скважин различного назначения.

Методы. Предложена технология ускоренного отделения шлама от бурового раствора, разработан мобильный универсальный комплекс для изготовления пропанта непосредственно в полевых условиях.

Результаты. Определены основные пути рециклинга бурового раствора, предложено устройство для омагничивания бурового раствора, для обжига пропанта предлагается использовать мобильный универсальный комплекс и попутньй газ. Разработанная технология получения пропанта дает существенный экономический и экологический эффект.
\end{abstract}

\section{Ключевые слова:}

Рециклинг бурового раствора, омагничивание, мобильная установка, шлам, пропант.

\section{Введение}

В настоящее время экологические вопросы во всем мире становятся все более актуальными. В результате человеческой деятельности степень загрязнения окружающей среды достигла катастрофических масштабов. Как никогда остро стоят эти вопросы и в нефтегазовой отрасли.

Технология бурения нефтегазовых скважин обуславливает образование технологических отходов, таких как: буровой шлам, отработанный буровой раствор и буровые сточные воды. Наибольшую трудность представляет утилизация отработанных буровых растворов и шламов.

Рециклинг бурового раствора включает в себя: разделение раствора на обезвоженную твердую фазу (буровой шлам) и дисперсную среду (буровой раствор); изготовление из бурового шлама различных видов сырья, необходимого для производства; по- вторное применение бурового раствора с целью сооружения скважин $[1,2]$.

Во многих странах, занимающихся бурением нефтегазовых скважин, используются различные методы рециклинга, или переработки образовавшихся при бурении скважин отходов с целью вторичного их использования для нужд производства.

Процесс идентификации или разделение отходов бурения на три основных вида: отработанный буровой раствор, буровой шлам и буровые сточные воды являются первостепенными технологическими задачами.

Объем отходов, образующихся при сооружении скважины, состоит из объема выбуренной породы и объема химреагентов и материалов, используемых при проводке скважины. В настоящее время до 80 \% объема бурения приходится на глинистые породы. Выбуренные частицы пород в процессе гидротранс- 
порта с забоя набухают, при этом объем шлама увеличивается на 20-25\%.

Многие буровые компании активно используют безамбарную технологию буровых работ с применением специальных емкостей. Традиционно используется четырехступенчатая очистка буровых растворов (высокоэффективные вибросита, пескоотделители или ситогидроциклонные установки, шламоотделители, центрифуги) [3, 4].

С целью интенсификации процесса отделения бурового шлама от раствора предлагается использовать блок омагничивания (рис. 1) [5, 6].

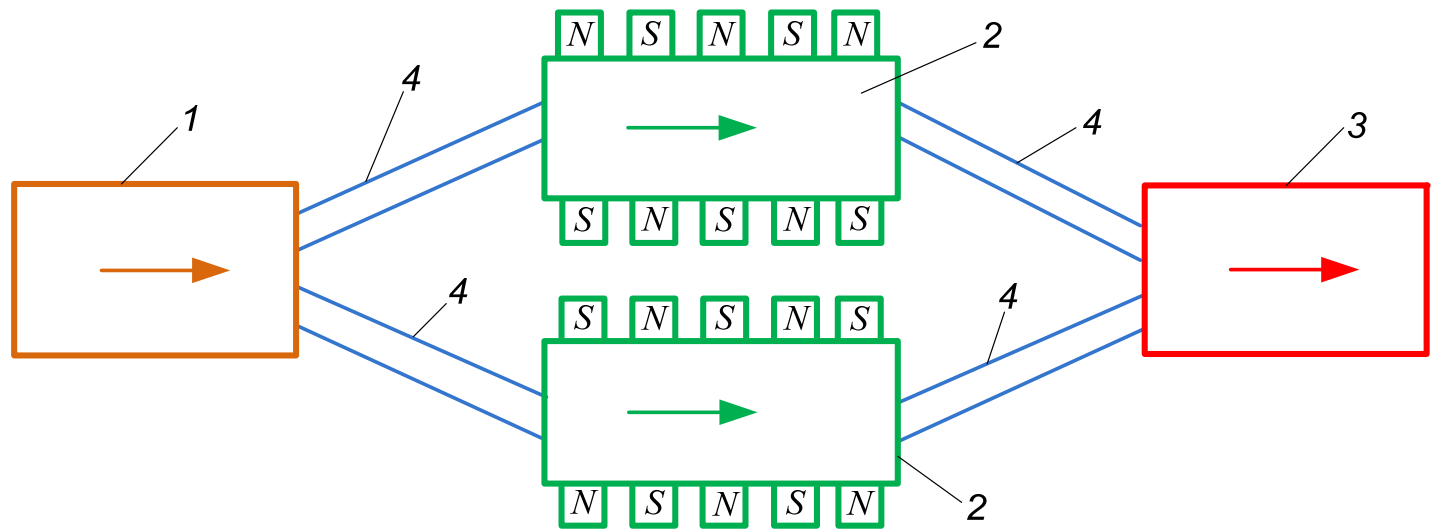

Рис. 1. Блок омагничивания промывочной жидкости: 1 - буровой насос; 2 - блок омагничивания; 3 - нагнетательный иланг; 4 - иланги

Fig. 1. Block for magnetizing flushing fluid: 1 - mud pump; 2 - magnetization block; 3 -delivery hose; 4 - hoses

Движение шлама от устья скважины до емкости для шлама показано на схеме очистки бурового раствора (рис. 2).

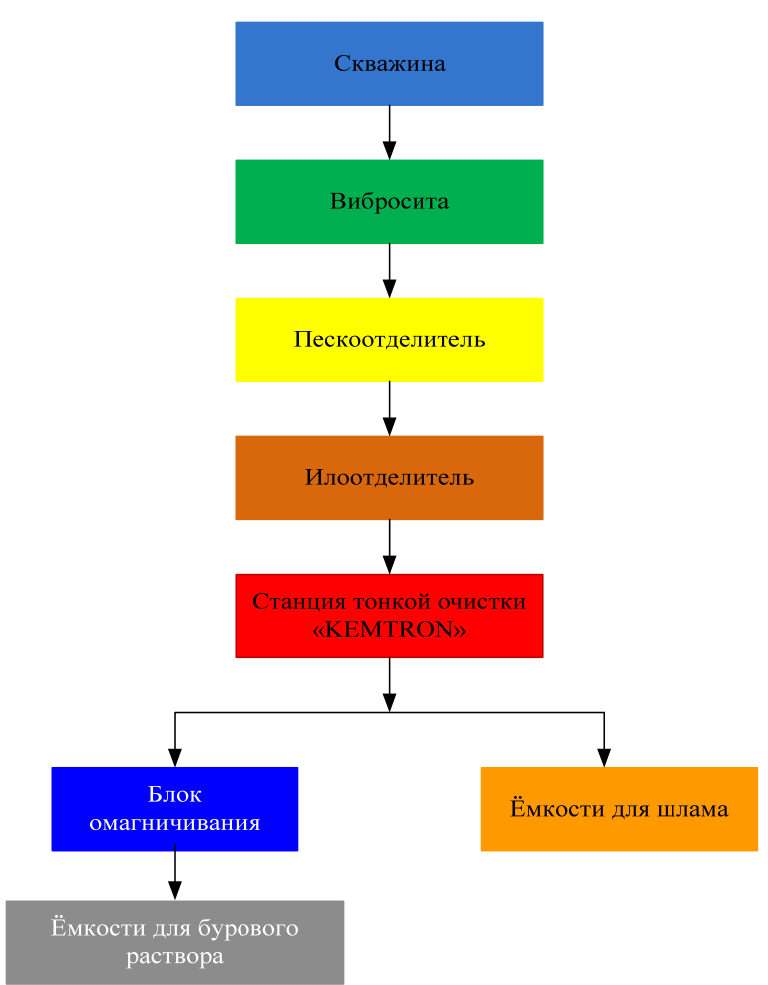

Рис. 2. Принципиальная схема очистки бурового раствора

Fig. 2. Schematic diagram of drilling mud cleaning

Подбор оптимальных реагентов для очистки отработанного бурового раствора и шлама является сложной технологической задачей.

\section{Результаты проведения лабораторных исследований}

Известно, что воздействие на буровой раствор различными физическими полями способствует ускоренному осадконакоплению [7, 8].

Определенный интерес представляет выявление зависимости магнитной обработки на скорость оседания частиц обработанной и необработанной промывочной жидкости. Для решения этой задачи в лабораторных условиях был смонтирован стенд, имитирующий циркуляционную систему скважины. Исследовали два типа промывочной жидкости: омагниченная и неомагниченная наноструктурированная, высокоингибированная. Опыты выполняли при магнитной напряженности до 3,0 тыс. Э, скорости пропускания жидкости $0,3 \mathrm{~m} / \mathrm{c}$, температуре до $45^{\circ} \mathrm{C}$. Время эксперимента составляло 40 минут [9].

Экспериментальные исследования показывают, что при магнитной обработке раствора максимальная интенсивность выпадения в осадок глинистых частиц наблюдается в течение 40 минут, причем для омагниченного раствора интенсивность осадковыпадения значительно выше, чем для неомагниченного.

Известно, что в глинистых породах присутствуют высокодисперсные ферромагнитные частицы. Это позволяет рассматривать буровой раствор как слабоферромагнитную систему.

Постоянное магнитное поле, очевидно, изменяет молекулярные Ван-дер-ваальсовые силы, поскольку они являются квантомеханическим эффектом, связанным с поведением электронов в атоме. При этом движение электронов и их энергия заметно изменяются при наложении магнитного поля. Превышение сил отталкивания над силами притяжения обуславливает возникновение силового барьера - начинается коагуляция частиц из раствора. 
Действие магнитного поля на суспензии коллоидных частиц приводит к характерным эффектам, в основе которых лежит способность частиц приобретать под действием поля направленное движение относительно среды. Под действием магнитного поля коллоидный раствор структурируется.

При нарушении агрегативной устойчивости характер оседания коллоидного раствора по существу и внешне сильно меняется; оседают не отдельные частицы, а флоккулы, причем в силу взаимодействия в этот процесс вовлечены сразу все флоккулы, мелкие и круглые частицы.

Находящиеся в растворе крупные частицы являются центром коагуляции. Число соударений, приводящих к слипанию мелких частиц с крупными, зависит от концентрации их в единице объема раствора. При отсутствии магнитного поля мелкие коллоидные частицы не прилипают к крупным. В магнитном поле даже низкой напряженности происходит коагуляция всех высокодисперсных частиц. Так как частицы достаточно малы по массе, для их осаждения требуется продолжительное время. С ростом числа частиц уменьшается вероятность их соударений и прилипание к крупным частицам, поэтому эффективность магнитной обработки с увеличением напряженности магнитного поля уменьшается. Этим можно объяснить минимум эффективности при максимуме напряженности магнитного поля [10].

Глинистая частица, обладающая тем или иным магнитным моментом, в условиях внешнего магнитного поля, рассматривается как носитель электрического заряда [9].

В связи с этим процесс коагуляции должен рассматриваться, на наш взгляд, не только с позиции баланса энергии молекулярного, электростатического и теплового происхождения, но еще и магнитного.

Осаждения частиц шлама в растворе описывается уравнением [10]:

$$
C \cdot r^{j}=\frac{H}{t}=V(r),
$$

где $V(r)$ - скорость оседания частиц с радиусом $r ; C$ константа; $j$ - показатель степени $(2,1,1 / 2) ; H$ напряженность магнитного поля, Э; $t$ - время, ч.

Моделирование процесса осадкообразования практически невозможно в силу большой сложности этого явления, поэтому природа осадкообразования может быть изучена только путем следования «от частного к общему», при учете известных закономерностей. При выполнении экспериментальных работ пришлось поступить так, как обычно поступают в этом случае, принимать значения других факторов постоянными и одинаковыми и исследовать при этом зависимость от интересующего нас фактора. В данном случае изучалась статистическая зависимость между напряженностью магнитного поля и содержанием глинистых частиц, выпавших в осадок.

Проведенные эксперименты позволили выявить ряд интересных закономерностей, а главное - дали возможность разобраться в природе наблюдаемых эффектов - почему омагниченный буровой раствор способствует увеличению осадконакопления шлама, что является важным моментом в технологии сооружения нефтегазовых скважин.

Определенный интерес представляет влияние магнитной обработки на скорость оседания частиц обработанной и необработанной промывочной жидкости. Для решения этой задачи в лабораторных условиях был смонтирован стенд, имитирующий циркуляционную систему скважины. Исследовали два типа бурового раствора: омагниченный и неомагниченный наноструктурированный, высокоингибированный (патент RU № 2708849) [8].

Осаждение глинистых частиц, после воздействия магнитного поля, наблюдали визуально и с помощью прибора ОМ-2. В каждом опыте производились наблюдения за интенсивностью коагуляции по характеру хлопьеобразования и просветлению осадка, его макроструктурными особенностями, трещиноватостью осадков, возникшей в результате сушки, за смещением частиц относительно вертикали и направлением внешнего магнитного поля. Опыты показали, что прозрачность неосевшей части суспензии различна. Так, в поле 1,0 тыс. Э она оказалась меньшей, чем в поле 2,0 тыс. Э, а осадок приобрел горизонтальноволнистую слоистость. Кроме того, мощность осадка в сильном магнитном поле значительно больше.

Каждую глинистую частицу можно рассматривать как микрообъект, находящийся в броуновском движении, перемещающийся с определенной скоростью в любом направлении и одновременно движущийся поступательно вниз. Нами наблюдалось смещение глинистых частиц в виде прилипших агрегатов на стенке цилиндра, что приводило к образованию наклонной слоистости. Полученная глинистой частицей величина ускорения является условной, так как частица находится в сложном тепловом движении, обладает оптимальной скоростью, подчиняется смещающему действию магнитного поля.

Анализ наблюдений за омагниченным наноструктурированным, высокоингибированным раствором позволяет сделать следующие выводы: а) наличие ферромагнитного компонента наблюдается в виде бурых скоплений на стенках цилиндра в районе полюсов магнита; б) коагуляция раствора зависит от напряженности магнитного поля; в) максимальная мощность зоны просветления наблюдается при напряженности 2,0 тыс. Э (рис. 3).

Экспериментальными исследованиями было установлено оптимальное время (40 минут) и эффективная температура осадконакопления $\left(40{ }^{\circ} \mathrm{C}\right)$ (рис. 4,5$)$.

Оценив выполненные эксперименты, можно утверждать: состав наноструктурированного, высокоингибированного бурового раствора оказывает существенного влияние на его магнитные свойства, частицы шлама различного состава содержат различное количество ферромагнетиков, этим можно объяснить его влияние на магнитные эффекты; воздействие магнитного поля увеличивает скорость осаждения частиц шлама из раствора, повышение температуры влияет на скорость осаждения частиц шлама из бурового раствора; в течение 40 минут основная масса шлама выпадает в осадок. 


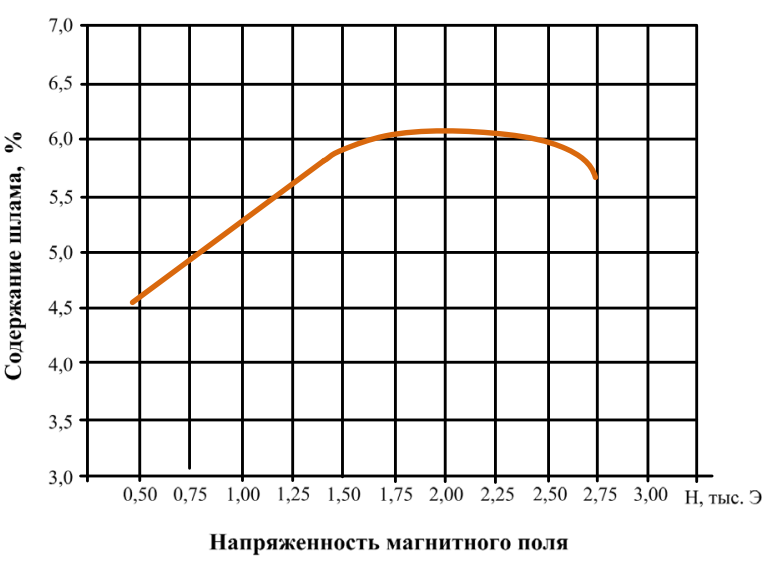

Рис. 3. Зависимость процентного содержания шлама, выпавшего в осадок в течение 40 минут, от напряженности магнитного поля

Fig. 3. Dependence of the percentage of sludge deposited in the sediment during 40 minutes, on magnetic field strength

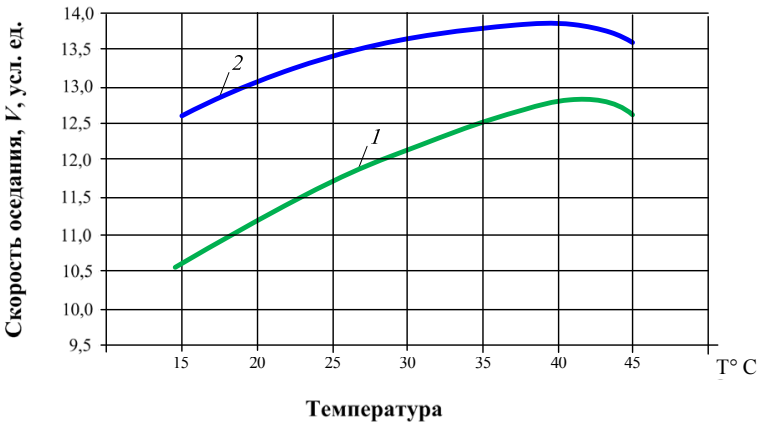

Pис. 4. Зависимость скорости осаждения глинистых частии наноструктурированного, высокоингибированного бурового раствора от температуpы: 1 - до омагничивания, 2 - после омагничивания

Fig. 4. Dependence of the sedimentation rate of clay particles of nanostructured, highly inhibited drilling fluid on temperature: 1 - before magnetization, 2 after magnetization

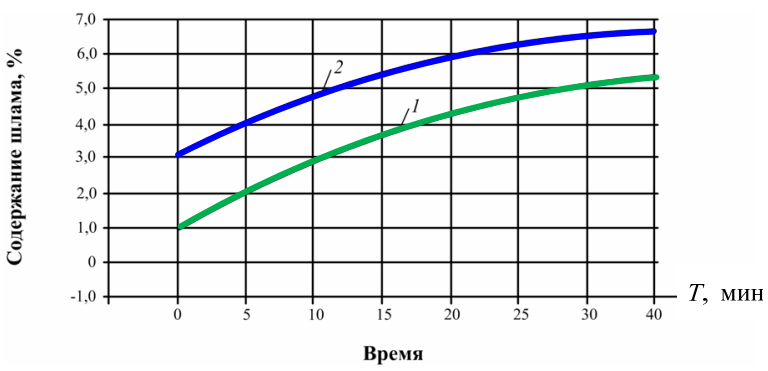

Рис. 5. Зависимость проиентного содержания шлама, выпавшего в осадок из наноструктурированного, высокоингибированного бурового раствора, от времени: 1 - до омагничивания, 2 - после омагничивания

Fig. 5. Dependence of the percentage of cuttings precipitated from the nanostructured, highly inhibited drilling fluid from time to time: 1 - before magnetization, 2 - after magnetization

Использование блока омагничивания промывочной жидкости с напряженностью постоянного маг- нитного поля до 3 тысяч эрстед позволило добиться, при экспериментальных исследованиях, увеличения скорости осаждения частиц шлама до двух раз.

По химическому составу отходы могут быть: глинистые, карбонатные, галоидносульфатные. Буровые компании используют различные методы утилизации буровых растворов, в частности $[11,12]$ :

1) для бурения новых скважин;

2) регенерация компонентов бурового раствора путём получения из него глинопорошка удовлетворительного качества и некоторых химических реагентов;

3) использованные в качестве добавок к тампонажным материалам;

4) физико-химическая нейтрализация и отверждение раствора и шлама.

При сооружении нефтегазовой скважины глубиной до 4000 м образуется до $600 \mathrm{~m}^{3}$ бурового шлама. Утилизация, обеззараживание и переработка шлама в настоящее время являются серьезными экологическими проблемами не только для нашей страны, но и за рубежом. Средняя стоимость утилизации $1 \mathrm{~m}^{3}$ бурового шлама в России составляет порядка 10000 рублей. Нами разработана технология получения пропанта из бурового шлама. Суть технологии заключается в следующем: полученный буровой шлам специальными химическими реагентами обеззараживается, добавляются химические добавки, окатыши из приготовленного шлама заданного диаметра обжигаются непосредственно на месторождении с использованием попутного газа.

Принципиальная схема универсального, перерабатывающего буровой шлам комплекса, смонтированного на шасси автомобиля высокой проходимости, показана на рис. 6 и включает следующее оборудование:

1) блок бурового шлама;

2) блок предварительной обработки шлама;

3) блок капсулирования шлама;

4) блок обжига шлама;

5) блок хранения пропанта.

Экономический эффект применения мобильной установки для изготовления пропанта достигается за счет:

1) отсутствия шламовых полигонов;

2) исключения затрат на транспортировку шлама на полигон захоронения;

3) уменьшения себестоимости изготовления пропанта за счет использования попутного газа разбуриваемого месторождения и изготовления пропанта на месторождении, а не на заводе;

4) рекультивации шламовых амбаров ранее пробуренных скважин;

5) выполнения гидроразрыва пласта с использованием пропанта, изготовленного на месторождении.

Для изготовления пропанта используются специальные химические добавки, повышающие прочность пропанта, разработана технология изготовления пропанта. Для обжига пропанта предлагается использовать мобильный универсальный комплекс с высокой степенью проходимости. 


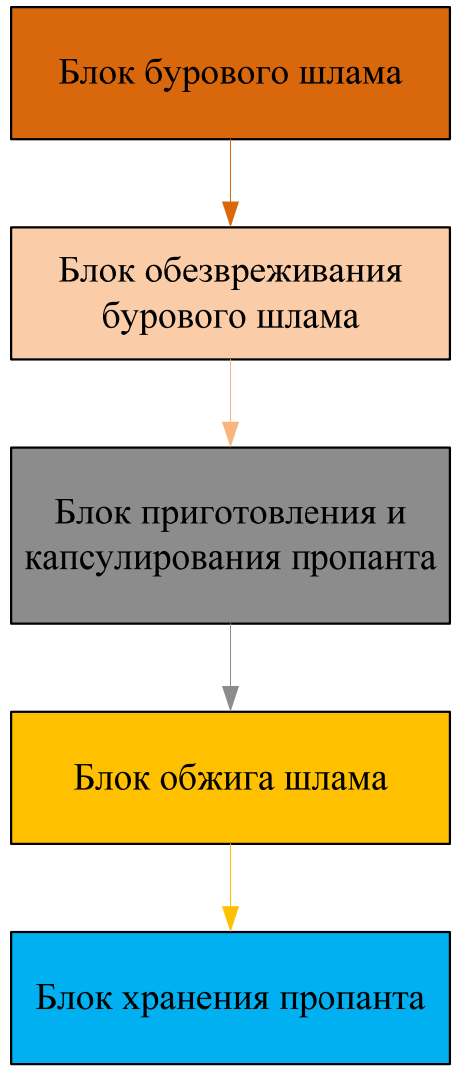

Pис. 6. Принципиальная схема мобильной установки для переработки бурового илама

Fig 6. Schematic diagram of a mobile plant for processing drill cuttings

Процесс переработки отходов буровых работ можно разделить на следующие операции [13, 14]:

- загрузка шлама в блок бурового шлама из контейнеров;

- очистка и обезвреживания бурового шлама;

- добавка химреагентов в шлам, приготовление и капсулирование пропанта;

- обжиг пропанта при температуре до $1400^{\circ} \mathrm{C}$;

- получение керамического пропанта с прочностью на сжатие до 50-55 МПа;

- складирование пропанта для хранения.

\section{СПИСОК ЛИТЕРАТУРЫ}

1. Губа А.С., Плетнева Н.И., Явич М.Ю. Идентификация отходов бурения // Нефть, газ, новации. - 2019. - № 11. - С. 82-86.

2. Матвиенко В.В., Кузнецова В.А., Цеханский М.В. К вопросу о современных методах переработки и утилизации отходов бурения // Нефть и газ Сибири. - 2017. - № 3 (28). - С. 147-151.

3. Буровой раствор для строительства скважин в сложных условиях / А.А. Третьяк, Ю.М. Рыбальченко, С.И. Лубянова, Ю.Ю. Турунтаев, К.А. Борисов // Нефтяное хозяйство. 2016. - № 2. - C. 28-31

4. Третьяк А.Я., Рыбальченко Ю.М. Теоретические исследования по управлению буровым раствором в осложненных условиях // Известия высших учебных заведений СевероКавказский регион. Технические науки. Приложение. 2006. - № 7. - C. 56-61.

5. Осипов Ю.Б. Поведение глинистых суспензий в магнитном поле // Геология. - 1964. - Сер. № 4. - С. 15-19.

6. О некоторых особенностях влияния электромагнитного поля на движение ионов в потоке раствора / В.К. Погодин, Ю.Я. Голгер, В.И. Классен, П.А. Смыслов // Применение
На разработанную технологию получения пропанта из отходов бурения подана заявка на изобретение. Таким образом, разработанная технология получения пропанта дает возможность получить существенный экономический и экологический эффект $[15,16]$.

В настоящее время в повестке дня буровых компаний довольно остро стоит вопрос переработки буровых отходов, особенно с учетом ужесточения экологических требований со стороны государственных служб. Предлагаемая технология получения пропанта основана на комплексном подходе, позволяющем решать вопросы утилизации шлама, сжигания попутного газа, производства пропанта на месте его применения, то есть на месторождении [17-20].

\section{Выводы}

1. Учитывая интенсивное развитие нефтегазодобывающей отрасли и ежегодное увеличение объема буровых работ, степень загрязнения окружающей среды будет увеличиваться.

2. Вопросы переработки и утилизации буровых отходов должны решаться с учетом требований законодательства.

3. Обработка промывочной жидкости в постоянном магнитном поле способствует ускоренному выпадению шлама из раствора в осадок.

4. Минералогический состав раствора оказывает существенное влияние на его магнитные свойства.

5. Переработка отходов, образующихся при строительстве скважин, в полезный продукт позволит не только решить экологические проблемы, но и может быть использована для различных целей.

6. Предлагаемые разработки по рециклингу бурового раствора позволят решить проблему обращения с отходами непосредственно на участках буровых работ, что даст значительный экономический эффект для буровых компаний.

Статья написана при финансовой поддержке Российского научного фонда в рамках соглашения РНФ № 20-79-10142 «Разработка эффективной технологии синтеза алюмосиликатных пропантов с использованием отходов бурения нефтегазовых скважин Южного федерального округа» (руководитель-Третьяк А.А.).

магнитной обработки воды в энергетике. Материалы Всесоюзного совещания. - Новосибирск, 1967. - С. 20-24.

7. Применение физических полей для регулирования свойств буровых растворов и тампонажных материалов / Н.М. Шерстнёв, С.П. Шандин, С.И. Толоконский, Н.О. Черская, А.В. Уголева // Российский химический журнал. 1995. - № 5. - T. 39. - C. 22-26.

8. Наноструктурированный, высокоингибированный буровой раствор: пат. Рос. Федерация, № 2708849, заявл. 24.01.19; опубл. 12.12.19. Бюл. № $35 .-8 \mathrm{c}$.

9. Высокоингибированный буровой раствор: пат. Рос. Федерация, № 2303047, заявл. 05.10.06; опубл. 20.07.07. Бюл. № 20. - 6 c.

10. Буровой раствор и управление его реологическими свойствами при бурении скважин в осложненных условиях / В.Ф. Чихоткин, А.Я. Третьяк, Ю.М. Рыбальченко, М.Л. Бурда // Бурение на нефть. - 2007. - № 7-8. - С. 58-60.

11. Caenn R., Darley H.C.H., Gray R.G. Chapter 14 - Drilling and Drilling Fluids Waste Management. - Composition and Properties of Drilling and Completion Fluids (Seventh Edition). Cambridge // Gulf Professional Publ., 2017. - P. 597-636. 
12. Sanzone D.M., Neff J.M., Vinhateiro N. Environmental fates and effects of ocean discharge of drill cuttings and associated drilling fluids from offshore oil and gas operations // IOGP Report 543. March 2016. - P. 4-10.

13. Можжерин А.В., Коржавин А.Ю. Исследование остаточной проводимости алюмосиликатных и магнезиально-кварцевых пропантов при циклических нагрузках // Бурение и нефть. 2017. - № 5. - C. 42-45.

14. Можжерин А.В., Коржавин А.Ю. Керамический пропант или песок? // Сфера. Нефть и газ. - 2018. - № 1. - С. 92-95.

15. BP p.l.c Statistical Review of World Energy 2019. 68th ed. - UK Pureprint Group Limited, 2019. - 61 p.

16. Hudgins C.M. Jr. Chemical use in North Sea oil and gas E\&P Journal of Petroleum Technology. - January 1994. - V. 46 (01). P. 67-74.
17. Differential-sticking mechanisms and a simple wellsite test for monitoring and optimizing drilling mud properties / P.I. Reid, G.H. Meeten, P. Clark, B.D. Chambers, A. Gilmour, M.W. Sanders // SPE Drilling \& Completion. - June 2000. V. 15. - № 15 (2). - P. 97-104. DOI: 10.2118/64114-PA

18. Hasan A.R., Kabir C.S. Two-phase flow in vertical and inclined annuli // International Journal of Multiphase Flow. - March 1992. - V. 18 (2). - P. 279-293.

19. Cobb M., Irvine M., Fichera M. Gas development, drill cuttings disposal - best practicable environmental option. - Edinburgh: ERM Worldwide Group Ltd, 2019. $-38 \mathrm{p}$

20. Rapold K. Drilling vibration measurement detect bit stick-slip // Oil and Gas Journal. - 1993. - № 9. - P. 66-70.

Поступила 23.12.2020 г.

\section{Информация об авторах}

Tретьяк A.A., доктор технических наук, доцент, профессор кафедры нефтегазовой техники и технологий Южно-Российского государственного политехнического университета (НПИ) им. М.И. Платова.

Яценко $\boldsymbol{E}$.А., доктор химических наук, профессор, заведующая кафедрой общей химии и технологии силикатов Южно-Российского государственного политехнического университета (НПИ) им. М.И. Платова.

Онофриенко $\boldsymbol{C}$.A., старший преподаватель кафедры нефтегазовой техники и технологий Южно-Российского государственного политехнического университета (НПИ) им. М.И. Платова.

Карельская E.B., инженер кафедры нефтегазовой техники и технологий Южно-Российского государственного политехнического университета (НПИ) им. М.И. Платова. 
UDC 622.24 .622

\title{
IDENTIFICATION OF DRILLING WASTES AND THEIR USE
}

\author{
Alexander A. Tretyak ${ }^{1}$, \\ 13050465@mail.ru
}

Elena A. Yatsenko', tksiww@yandex.ru

Sergey A. Onofrienko', 13050465@mail.ru

\author{
Ekaterina V. Karelskaya ${ }^{1}$, \\ karelskaya_1992@mail.ru \\ 1 M.I. Platov South-Russian State Polytechnic University (NPI), \\ 132, Prosveshcheniya street, Novocherkassk, Russia.
}

The relevance of the study is caused by the need to solve environmental issues arising during the construction of oil and gas wells. Identification of wastes generated during the construction of wells and their use for the needs of the national economy are the urgent tasks now. Mud recycling issues include: mud separation into dewatered solids (drill cuttings) and dispersed media (drilling mud); production of various types of raw materials from drill cuttings: drilling mud reuse. In order to intensify separation of drill cuttings from the solution, it is proposed to use magnetization. A schematic diagram of drilling mud cleaning using a magnetization unit is proposed. It was found that the magnetization of the drilling fluid helps accelerating the fallout of cuttings from the solution. We offer the technology for obtaining proppant from drill cuttings using associated gas for roasting and a mobile complex that functions directly in the field, on the deposits. The article provides a schematic diagram of a mobile unit for processing drill cuttings. The proppant, prepared from drill cuttings, is proposed to be used for hydraulic fracturing in the fields located in this area. The proposed developments for recycling drilling mud will allow solving the problem of waste management directly at the drilling sites, which will give a significant economic effect for drilling companies.

The aim of the research is to evaluate the issues of drilling mud recycling; solve the issues of accelerated separation of cuttings from drilling mud using a magnetic field; to develop a mobile unit for processing drill cuttings using associated gas for proppant firing; to apply for an invention and obtain a patent on the developed technology for producing proppant from drilling waste.

Objects: sludge obtained during the construction of wells for various purposes.

Methods. A technology for accelerated separation of cuttings from drilling mud was proposed, a mobile universal complex was developed for the manufacture of proppant directly in the field.

Results. The main ways of recycling drilling mud were determined, a device for magnetizing drilling mud was proposed. A mobile universal complex and associated gas were proposed to use for proppant burning. The developed proppant production technology makes it possible to obtain significant economic and environmental benefits.

\section{Key words:}

Recycling of drilling mud, magnetization, mobile installation, sludge, proppant.

The article was financially supported by the Russian Science Foundation within the agreement of the RSF no. 20-79-10142 «Development of the efficient technique of synthesis of aluminosilicate proppants using the drilling wastes of oil-and-gas wells in Southern Federal District» (manager - A.A. Tretyak).

\section{REFERENCES}

1. Guba A.S., Pletneva N.I., Yavich M.Yu. Drilling waste identification. Oil, gas, innovations, 2019, no. 11, pp. 82-86. In Rus.

2. Matvienko V.V., Kuznetsova V.A., Tsekhansky M.V. About the issue of modern methods of processing and disposal of drilling waste. Oil and Gas of Siberia, 2017, no. 3, pp. 147-151. In Rus.

3. Tretyak A.A., Rybalchenko Yu.M., Lubyanova S.I., Turuntaev Yu.Yu., Borisov K.A. Drilling fluids for the construction of wells in complex conditions. Oil industry, 2016, no. 2, pp. 28-31. In Rus.

4. Tretyak A.Ya., Rybalchenko Yu. M. Theoretical research on drilling fluid management in complicated conditions Izvestiya of higher educational institutions. North Caucasian region. Technical science. Application, 2006, no. 7, pp. 56-61. In Rus.

5. Osipov Yu.B. Behavior of clay suspensions in a magnetic field Geology, 1964, no. 4, pp. 15-19.

6. Pogodin V.K., Golger Yu.Ya., Klassen V.I. On some features of the influence of the electromagnetic field on the movement of ions in the flow of solution. Application of magnetic water treatment in power engineering. Materials of the All-Union meeting. Novosibirsk, 1967, pp. 20-24.

7. Sherstnev N.M., Shandin S.P., Tolokonsky S.I., Cherskaya N.O., Ugoleva A.V. Application of physical fields to control the proper- ties of drilling fluids and grouting materials. Russian chemical journal, 1995, V. 39, no. 5, pp. 22-26. In Rus.

8. Tretyak A.A., Onofrienko S.A. Nanostrukturirovanny, vysokoingibirovanny burovoy rastvor [Nanostructured, highly inhibited drilling mud]. Patent RF, no. 2708849, 2019.

9. Tretyak A.Ya., Mnatsakanov V.A., Zaretsky V.S., Shamanov S.A., Frolov P.A., Chikhotkin V.F., Rybalchenko Yu.M. Vysokoingibirovanny burovoy rastvor [Highly inhibited drilling mud]. Patent RF, no. 2303047, 2007.

10. Chikhotkin V.F., Tretyak A.Ya., Rybalchenko Yu.M., Burda M.L. Drilling fluid and control of its rheological properties when drilling wells in difficult conditions. Drilling for oil, 2007, no. 7-8, pp. 58-60. In Rus.

11. Caenn R., Darley H.C.H., Gray R.G. Chapter 14 - Drilling and Drilling Fluids Waste Management. Composition and Properties of Drilling and Completion Fluids (Seventh Edition). Cambridge, Gulf Professional Publ., 2017. pp. 597-636.

12. Sanzone D.M., Neff J.M., Vinhateiro N. Environmental fates and effects of ocean discharge of drill cuttings and associated drilling fluids from offshore oil and gas operations. IOGP Report 543, March 2016, pp. 4-10. 
13. Mozhzherin A.V., Korzhavin A.Yu. Studies of the residual conductivity of alumino-silicate and magnesian-quartz proppants under cyclic loads. Drilling and oil, 2017, no. 5, pp. 42-45. In Rus.

14. Mozhzherin A.V., Korzhavin A.Yu. Ceramic proppant or sand? Sphere. Oil and gas, 2018, no. 1, pp. 92-95. In Rus.

15. BP p.l.c Statistical Review of World Energy 2019. $68^{\text {th }}$ ed. UK, Pureprint Group Limited, 2019, $61 \mathrm{p}$.

16. Hudgins C.M. Jr. Chemical use in North Sea oil and gas E\&P. Journal of Petroleum Technology, January 1994, vol. 46 (01), pp. 67-74.

17. Reid P.I., Meeten G.H., Clark P., Chambers B.D., Gilmour A., Sanders M.W. Differential-sticking mechanisms and a simple wellsite test for monitoring and optimizing drilling mud properties.
SPE Drilling \& Completion, June 2000, vol.15, no. 15 (2), pp. 97-104. DOI: 10.2118/64114-PA

18. Hasan A.R., Kabir S. Two-phase flow in vertical and inclined annuli. International Journal of Multiphase Flow, March 1992, no. 18 (2), pp. 279-293.

19. Cobb M., Irvine M., Fichera M. Gas development, drill cuttings disposal - best practicable environmental option. Edinburgh, ERM Worldwide Group Ltd., 2019, 38 p.

20. Rapold K. Drilling vibration measurement detect bit stick-slip. Oil and Gas Journal, 1993, vol. 91, no. 9, pp. 66-70.

Received: 23 December 2020.

\section{Information about the authors}

Alexander A. Tretyak, Dr. Sc., professor, M.I. Platov South-Russian State Polytechnic University (NPI).

Elena A. Yatsenko, Dr. Sc., professor, head of the General chemistry and technology of silicates department, M.I. Platov South-Russian State Polytechnic University (NPI).

Sergey A. Onofrienko, senior lecturer, M.I. Platov South-Russian State Polytechnic University (NPI).

Ekaterina V. Karelskaya, engineer, M.I. Platov South-Russian State Polytechnic University (NPI). 